\title{
Small Animal PET Imaging of hTERT RNA-Targeted HSV1-tk Gene Expression with Trans-Splicing Ribozyme
}

\author{
Min-Jung Seo, Ju Hui Park, Kyo Chul Lee, ${ }^{1}$ Yong Jin Lee, ${ }^{1}$ Tae Sup Lee, ${ }^{1}$ \\ Tae Hyun Choi, ${ }^{1}$ Seong-Wook Lee, ${ }^{2}$ Kwang II Kim, ${ }^{1}$ and Joo Hyun Kang ${ }^{1}$
}

\begin{abstract}
Background: Trans-splicing ribozymes (TSR) are useful anticancer agents targeting cancer-specific transcripts and replacing the RNA to induce anticancer gene expression specifically and selectively in cancer cells. Similar to other gene therapy methods, it is also important to evaluate the transgene expression for target specificity and ribozyme activity.

Materials and Methods: In this study, the authors performed in vivo small animal positron emission tomography (PET) imaging and biodistribution assay to evaluate human telomerase reverse transcriptase (hTERT) RNA-targeting-specific TSR, which directs the expression of herpes simplex virus type 1 thymidine kinase (HSV1-tk) gene selectively in hTERT-positive tumors through targeted RNA replacement of the hTERT transcript.

Results: The hTERT RNA-targeted HSV1-tk expression with TSR was monitored by PET imaging with ${ }^{124}$ I labeled $2^{\prime}$-fluoro-2'-deoxy-1- $\beta$-D-arabinofuranosyl-5-iodouracil, which is one of the thymidine derivatives acting as substrates for HSV1-tk, in hTERT-positive tumor-bearing mice.

Conclusions: Imaging of hTERT RNA-targeted HSV1-tk expression by TSR could be used in the development of advanced gene therapy using tumor-specific TSR.
\end{abstract}

Keywords: hTERT, PET imaging, trans-splicing ribozyme

\section{Introduction}

G ene therapy has been studied as an alternative therapeutic approach in cancer by three main strategies, including the replacement of the mutant gene with a normal gene, silencing of a mutated gene, and genetic approaches to directly kill the cancer cells. Specific and safe gene targeting are essential to achieve these strategies effectively without adverse effects. ${ }^{1}$ Trans-splicing ribozymes (TSR) based on Tetrahymena group I intron mediate the cleavage of target RNA and trans-ligation of an exon attached at their $3^{\prime}$ end to the downstream U nucleotide of the cleaved target RNA. ${ }^{2}$ Therefore, TSR has been reported as a useful anticancer agent by cancer-specific transcript targeting and RNA replacement to induce anticancer gene activities specifically and selectively in cancer cells. ${ }^{3-6}$

Even though TSR are stable and specific for in vivo applications, it is still important to evaluate the transgene expression to verify target specificity and activity of ribozyme. Molecular imaging methods using reporter gene are most appropriate for the evaluation of TSR because target specificity and activity of ribozyme are directly correlated with the expression of transgene, reporter gene. Reporter gene imaging provides noninvasive evaluation of endogenous biological processes in living subjects and is performed using various imaging modalities. ${ }^{7-10}$

A few studies reported that endogenous mRNAs can be imaged by TSR and optical imaging reporter genes in cultured cells or tumor-bearing mouse models. ${ }^{11-13}$ However, although optical imaging using fluorescence or bioluminescence reporter gene is associated with increased sensitivity or resolution, its clinical application is limited due to attenuation, scattering, and differential absorption of light by tissues resulting in poor quantification. ${ }^{14}$ Conversely, radionuclide imaging based on accumulated radioactivity that reflects the expression of the reporter genes facilitates

${ }^{1}$ Division of Applied RI, Korea Institute of Radiological and Medical Sciences, Seoul, Korea.

${ }^{2}$ Department of Integrated Life Sciences, Research Institute of Advanced Omics, Dankook University, Yongin, Korea.

Address correspondence to: Kwang Il Kim; Division of Applied RI, Korea Institute of Radiological and Medical Sciences; 75, Nowon-ro, Nowon-gu, Seoul 01812, Korea

E-mail: kikim@kirams.re.kr 
accurate quantification in human subjects as well as in small animals.

The authors used an adenovirus carrying human telomerase reverse transcriptase (hTERT) RNA-specific transsplicing ribozyme that contains the herpes simplex virus 1 thymidine kinase (HSV1-tk) gene previously reported. ${ }^{6}$ HSV1-tk can be used as a reporter gene as well as a suicide therapeutic gene, and when coupled to $2^{\prime}$-fluoro- $2^{\prime}$-deoxy-1$\beta$-D-arabinofuranosyl-5-[ $\left.{ }^{124} \mathrm{I}\right]$ iodouracil ([$\left.\left.{ }^{124} \mathrm{I}\right] \mathrm{FIAU}\right)$ or 9(4- $\left[{ }^{18} \mathrm{~F}\right]$ fluoro-3-(hydroxymethyl)butyl)guanine ( $\left.\left[{ }^{18} \mathrm{~F}\right] \mathrm{FHBG}\right)$, it is the first and most widely used radionuclide-based reporter system. ${ }^{15-18}$ Radiolabeled FIAU is highly resistant to metabolic degradation because of the protective group in 2 '-fluoro, which acts against enzymatic cleavage of the $\mathrm{N}$ glycosyl linkage by nucleoside phosphorylases. ${ }^{19}$ Furthermore, Chou et al. reported that $2^{\prime}$-fluoro substituent resists catabolism and this property increases metabolic stability in vivo. ${ }^{20}$

In this study, the authors performed an in vivo small animal positron emission tomography (PET) imaging and biodistribution assay with $\left[{ }^{124}\right.$ I]FIAU to evaluate the hTERT RNA-targeting TSR, which directs the expression of HSV1-tk gene selectively in hTERT-positive tumor by targeted RNA replacement of the hTERT transcript.

\section{Materials and Methods}

\section{Recombinant adenoviruses}

Ad-Rz-HSV1tk containing hTERT-specific TSR and HSV1-tk, and Ad-HSV1tk, as a control, containing HSV1-tk driven by the cytomegalovirus promoter were constructed and generated as described (Fig. 1). ${ }^{4,6}$

\section{Cell culture}

The hTERT-positive human colon cancer cells (HT-29) were cultured in Dulbecco's modified Eagle's medium (DMEM) and hTERT-negative normal human lung fibro- blast cells (IMR-90) were cultured in minimum essential medium supplemented with $10 \%$ fetal bovine serum, $100 \mathrm{U} / \mathrm{mL}$ penicillin, $100 \mathrm{~g} / \mathrm{mL}$ streptomycin, and $250 \mathrm{ng} / \mathrm{mL}$ amphotericin $\mathrm{B}$ in an atmosphere containing $5 \% \mathrm{CO}_{2}$ at $37^{\circ} \mathrm{C}$.

\section{$\left[^{124 / 125}\right.$ I]FIAU synthesis}

Radiolabeling was performed as previously described with a few modifications. ${ }^{21} \mathrm{Na}^{124}$ I (MC-50 cyclotron; Korea Institute of Radiological and Medical Sciences [KIRAMS], Seoul, Korea) or $\mathrm{Na}^{125}$ I (Perkin Elmer, Inc., Waltham, MA) was added to a solution containing stannylated precursor, $2^{\prime}$ fluoro- 2 -deoxy-1- $\beta$-D-arabinofuranosyl-5-(tri-n-butyltin)uracil ( $25 \mu \mathrm{g}$; FutureChem Co., Seoul, Korea), followed by the addition of $30 \%$ hydrogen peroxide/acetic acid (1:3, $\mathrm{v} / \mathrm{v})$. After quenching with aqueous saturated sodium metabisulfite, the radioiodinated FIAU was isolated on a C18 Sep-Pak cartridge (Waters Corp., Milford, MA), and eluted with ethanol. The ethanol was evaporated and the radioiodinated FIAU was formulated with a cell culture medium or saline.

The overall radiochemical yields were $40 \% \pm 2 \%$ for $\left[{ }^{124}\right.$ I]FIAU and $70 \% \pm 3 \%$ for $\left[{ }^{125}\right.$ I]FIAU. Radiochemical purities measured by radio-high-performance liquid chromatography, as previously described, ${ }^{22}$ were over $98 \%$ and molar activities about $700 \mathrm{MBq} / \mu \mathrm{mol}$ for $\left[{ }^{124} \mathrm{I}\right] \mathrm{FIAU}$ and $34 \mathrm{MBq} / \mu \mathrm{mol}$ for $\left[{ }^{125}\right.$ I]FIAU.

\section{In vitro analysis of transgene activity by TSR}

To validate HSV1-tk gene expression by a trans-splicing reaction, HT-29 and IMR-90 cells were seeded in six-well plates at densities of $5 \times 10^{5}$ and $2 \times 10^{5}$, respectively, per well. After overnight incubation at $37^{\circ} \mathrm{C}$, cells were infected with adenovirus at various multiplicity of infection and maintained for $24 \mathrm{~h}$ in serum-free media. The transfection efficiency of adenoviruses was established by reverse

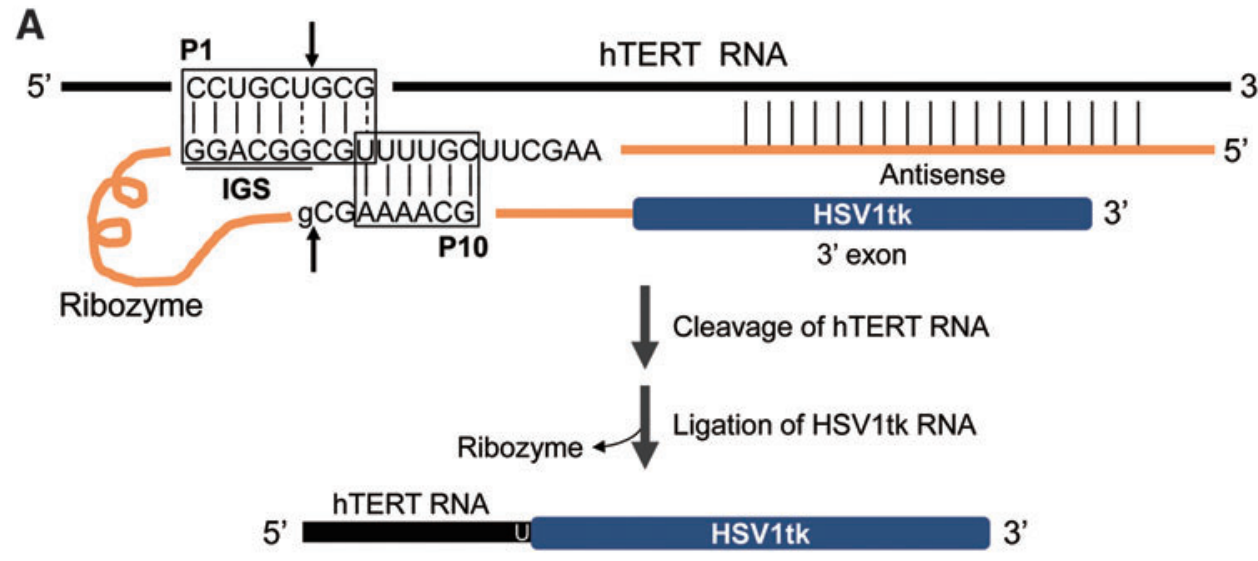

B

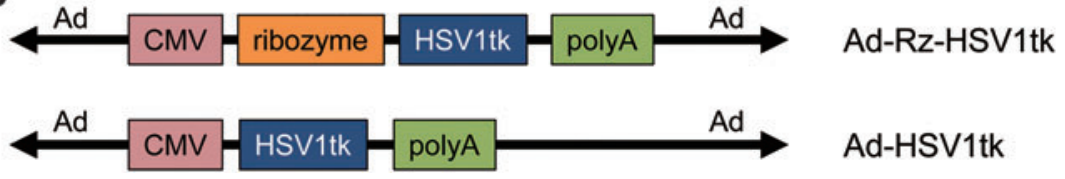

FIG. 1. Schematic diagram of hTERT-dependent selective expression of HSV1-tk RNA. (A) Ribozymemediated selective expression of HSV1-tk RNA by hTERT-targeting trans-splicing, (B) recombinant adenoviral vectors. HSV1-tk, herpes simplex virus type 1 thymidine kinase; hTERT, human telomerase reverse transcriptase. Color images are available online. 
transcription-polymerase chain reaction (RT-PCR) analysis of HSV1-tk gene expression in all adenovirus-infected cells.

PCR analysis was conducted with total RNA prepared using the Easy-Spin ${ }^{\mathrm{TM}}$ RNA extraction kit (iNtRON Biotechnology, Seongnam, Korea). Complementary DNA (cDNA) synthesis was performed with Superscript III reverse transcriptase (Invitrogen, Carlsbad, CA). PCR amplifications of individual cDNA were performed $\left(95^{\circ} \mathrm{C}\right.$ for $5 \mathrm{~min}$; 30 cycles at $95^{\circ} \mathrm{C}$ for $30 \mathrm{~s}$ and $57^{\circ} \mathrm{C}$ for $30 \mathrm{~s}$; and $72^{\circ} \mathrm{C}$ for $30 \mathrm{~s}$ and $72^{\circ} \mathrm{C}$ for $5 \mathrm{~min}$ ) using Maxime PCR PreMix Kit (i-Star Taq) (iNtRON Biotechnology) and specific primers. The oligonucleotide primer sequences were as follows: $\beta$-actin; sense (5'-GTGGGGCGCCCCAGGCACCAG-3'), antisense (5'-CTCCTTAATGTCACGCACGAT-3'), HSV1-tk; sense (5'-GCGAACATCTACACCACCCA-3'), antisense (5'-AGTGAGCCTCCCCCATCTC-3'), and hTERT; sense (5'-CGGAAGAGTGTCTGGAGCAA-3'), antisense (5'-GG ATGAAGCGGAGTCTGGA-3').

To detect trans-spliced molecules (TSM), the first PCR was performed with a $5^{\prime}$ primer specific for the transsplicing junction (5'-GGGGAATTCA GCGCTGCGTCC$\left.3^{\prime}\right)$ and with HSV1-tk (5'-GTTATCTGGGCGCTTGTCAA-3'). A second PCR was conducted with inward primers: 5'-GCTGCGTCCTGCTAAAAC-3' and 5'-CAGTAGCGTG GGC ATTTTCT-3'. ${ }^{23}$ Amplified products were analyzed by ethidium bromide-stained agarose gel electrophoresis. Results were interpreted using Multi Gauge V3.0 (Fujifilm, Tokyo, Japan). Expression values of $h T E R T$, HSV1-tk, and TSM genes were normalized with $\beta$-actin.

The uptake assay of $\left[{ }^{125} \mathrm{I}\right] \mathrm{FIAU}$ was performed by incubating infected cells at $37^{\circ} \mathrm{C}$ for 10,60 , and $120 \mathrm{~min}$ with $\left[{ }^{125}\right.$ I]FIAU (74 kBq per well) in the culture medium. After incubation, the medium was removed, and the cells were washed twice with ice-cold phosphate buffered saline. The cells were harvested by treatment with $0.5 \%$ trypsin and resuspended in culture medium to neutralize the trypsin. The cellular accumulation of radioactivity was measured using a gamma counter (1480 WIZARD; PerkinElmer, Inc.) and normalized to the number of viable cells. Data represent the mean \pm standard deviation of three wells.

\section{Animal study}

Animal care, maintenance, and treatment in these studies followed the protocols approved by the Institutional Animal Care and Use Committee of the Korea Institute of Radiological and Medical Sciences. Housing conditions for mice were controlled with $12 \mathrm{~h}$ light/ $12 \mathrm{~h}$ dark cycle (lights on at 8:00 AM), temperature $23 \pm 2^{\circ} \mathrm{C}$, and humidity $40 \%-60 \%$.

Xenografts were produced in 6-week-old female Balb/cnu/nu mice $(n=15)$ (Nara Biotech., Seoul, Korea) through subcutaneous injection of $1 \times 10^{7}$ tumor cells in $100 \mu \mathrm{L}$ of serum-free cell culture medium. Adenoviruses at a concentration of $1 \times 10^{9} \mathrm{pfu}$ in $100 \mu \mathrm{L}$ of saline were injected into the tumor or muscle when the tumors reached a diameter of 8-11 mm, and PET images were acquired at $48 \mathrm{~h}$ postinjection. At this time, the average body weight of the mice was $23.85 \pm 1.26 \mathrm{~g}$. Potassium perchlorate $(100 \mathrm{mg} / \mathrm{kg})$ was administered orally $2 \mathrm{~h}$ before $\left[{ }^{124} \mathrm{I}\right]$ FIAU injection and intraperitoneally just before imaging. At the end of the experiment, the authors performed $\mathrm{CO}_{2}$ euthanasia with flow rate of $10 \%-30 \%$ of the cage volume per minute.

\section{In vivo PET imaging and biodistribution}

The mice were anesthetized with $2 \%$ isoflurane in oxygen and injected with $7.4 \mathrm{MBq}$ of $\left[{ }^{124} \mathrm{I}\right]$ FIAU into the tail vein and maintained under normal conditions for $2 \mathrm{~h}$, to obtain an acceptable PET image. PET images were acquired using an Inveon small animal PET/SPECT/CT system (Siemens Medical Solutions) and MicroPETR4 scanner (Concorde Microsystems, Knoxville, TN). PET images were scanned under a 1,200 s acquisition time and a $511 \mathrm{KeV}$ energy level (low level $=350 \mathrm{KeV}$ and upper level $=650$ or $750 \mathrm{KeV}$, respectively). During acquisition of the PET images, mice were anesthetized using $2 \%$ isoflurane. The level of radioactivity in tumor was measured as $\%$ injected dose per gram by region of interest (ROI), which normalizes the activity for body weight and injected activity. Reconstruction of data set was accomplished using Inveon Research Workplace software (Siemens Medical Solutions).

The biodistribution study was conducted by euthanizing the mice and collecting tissues (blood, heart, liver, lung, spleen, kidney, stomach, small intestine, large intestine, muscle, and tumor) at $48 \mathrm{~h}$ postinjection of $\left[{ }^{124}\right.$ I]FIAU. All tissues were weighed and their radioactivity was measured with a $\gamma$-counter (1480 WIZARD; Perkin Elmer, Inc.).

\section{Statistical analysis}

Data were expressed as the mean \pm standard error of the mean. Unpaired two-tailed Student's $t$-test was used to compare the two groups. A value of $p<0.05$ was considered statistically significant.

\section{Results}

\section{Selective induction of transgene expression} by Ad-Rz-HSV1tk in hTERT-positive cancer cells

HT-29 and IMR-90 cells were infected with Ad-HSV1tk or Ad-Rz-HSV1tk adenovirus. At $24 \mathrm{~h}$ postinfection, the authors performed RT-PCR to investigate the gene expression of hTERT, HSV1-tk, and TSM in HT-29 and IMR-90 cells (Fig. 2). In HT-29 cells, the hTERT-positive cells, hTERT gene expression was observed in the control group as well as the groups infected with Ad-HSV1tk and Ad-RzHSV1tk. Conversely, in hTERT-negative IMR-90 cells, hTERT gene expression was not observed in any groups.

The expression level of HSV1-tk RNA fused with the ribozyme in all Ad-Rz-HSV1tk-infected cells was consistent with that of HSV1-tk RNA in all Ad-HSV1tk-infected cells, suggesting that the ribozyme expression level in both cells did not affect the induction of functional HSV1-tk RNA. Otherwise, hTERT-dependent TSM expression by ribozyme was observed in Ad-Rz-HSV1tk-infected HT-29 cells alone. These results demonstrate that Ad-Rz-HSV1tkinduced TSM expression occurred specifically in hTERTpositive cells.

\section{Evaluation of HSV1-tk activity induced by Ad-Rz-HSV1tk in HT-29 and IMR-90 cells}

The authors investigated whether ribozyme HSV1-tk specifically induces the accumulation of FIAU in hTERTexpressing cancer cells through $\left[{ }^{125}\right.$ I]FIAU uptake study. 


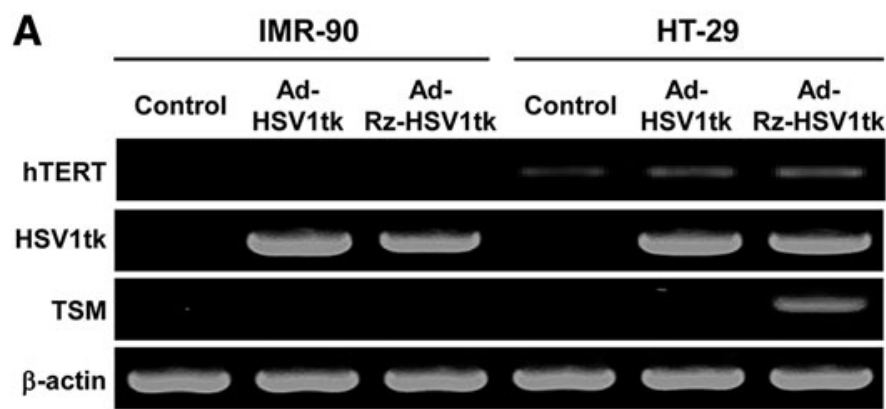

B hTERT

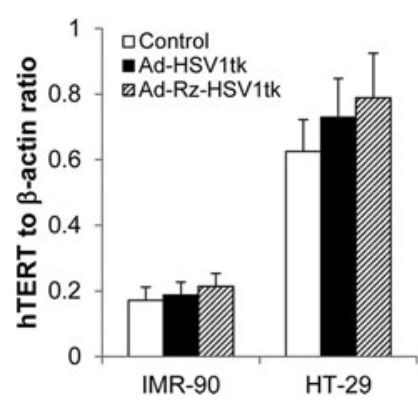

HSV1tk

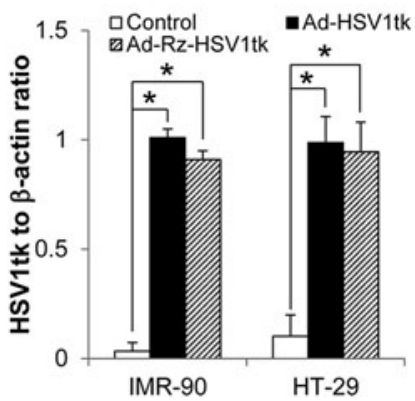

TSM

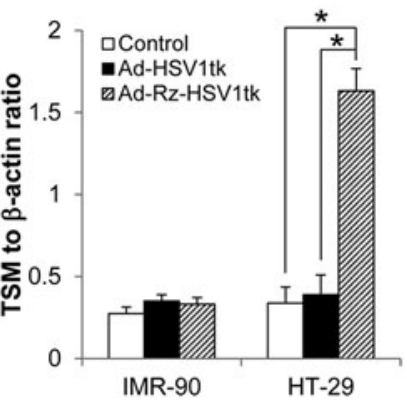

FIG. 2. The hTERT RNAdependent HSV1-tk expression in hTERT-negative (IMR-90) and hTERTpositive (HT-29) cells. (A) Detection of transspliced molecules in adenovirus-infected cells by RT-PCR, (B) quantitative analysis of gene expression normalized with $\beta$-actin $\left({ }^{*} p<0.05\right)$.
Figure 3 shows HSV1-tk activity detected by $\left[{ }^{125}\right.$ I]FIAU uptake in HT-29 and IMR-90 cells. Adenovirus-infected cells were incubated for 10,60 , and $120 \mathrm{~min}$ in $\left[{ }^{125} \mathrm{I}\right] \mathrm{FIAU}$ containing media, followed by measurement of $\left[{ }^{125}\right.$ I]FIAU uptake using a $\gamma$-counter. In HT-29, HSV1-tk activities of Ad-HSV1tk- and Ad-Rz-HSV1tk-infected groups increased time dependently, whereas in IMR-90, the HSV1-tk activity increased in the Ad-HSV1tk-infected group alone. These data indicate that $\left[{ }^{125} \mathrm{I}\right]$ FIAU uptake driven by HSV1-tk activation depends on the presence of hTERT in Ad-RzHSV1tk-infected cells.

\section{Imaging hTERT mRNA expression using ribozyme HSV1-tk in HT-29 tumor-bearing mice}

To investigate the hTERT-positive cancer targeting by ribozyme HSV1-tk through $\left[{ }^{124}\right.$ I]FIAU PET imaging, the authors generated tumor-bearing $\mathrm{BALB} / \mathrm{c}$ nude mice by subcutaneous injection of HT-29 cells dorsally into the right shoulders. After 2 weeks, they divided the mice into two groups and intratumorally injected saline as control $(n=5)$ and Ad-Rz-HSV1tk $(n=5)$, respectively. At $48 \mathrm{~h}$ after adenovirus injection, $\left[{ }^{124} \mathrm{I}\right] \mathrm{FIAU}(7.4 \mathrm{MBq} / \mathrm{head})$ was administered to tail vein of the mouse and imaged using PET at $2 \mathrm{~h}$ postinjection (Fig. 4A). According to ROI analysis, the ${ }^{124}$ I]FIAU uptake in the Ad-Rz-HSV1tk-infected HT-29 group was significantly higher $(1.54 \pm 0.34 \% \mathrm{ID} / \mathrm{g})$ than in the control group $(1.06 \pm 0.17 \% \mathrm{ID} / \mathrm{g})(p=0.02)$, although it was lower than in the Ad-HSV1tk group (data now shown) (Fig. 4B).

Figure 5A illustrates the comparative $\left[{ }^{124} \mathrm{I}\right] \mathrm{FIAU}$ uptake of HT-29 tumor and normal muscle with or without Ad-RzHSV1tk infection. In control mice, muscle and HT-29 tumors showed no $\left[{ }^{124} \mathrm{I}\right]$ FIAU uptake $(n=2)$. However,
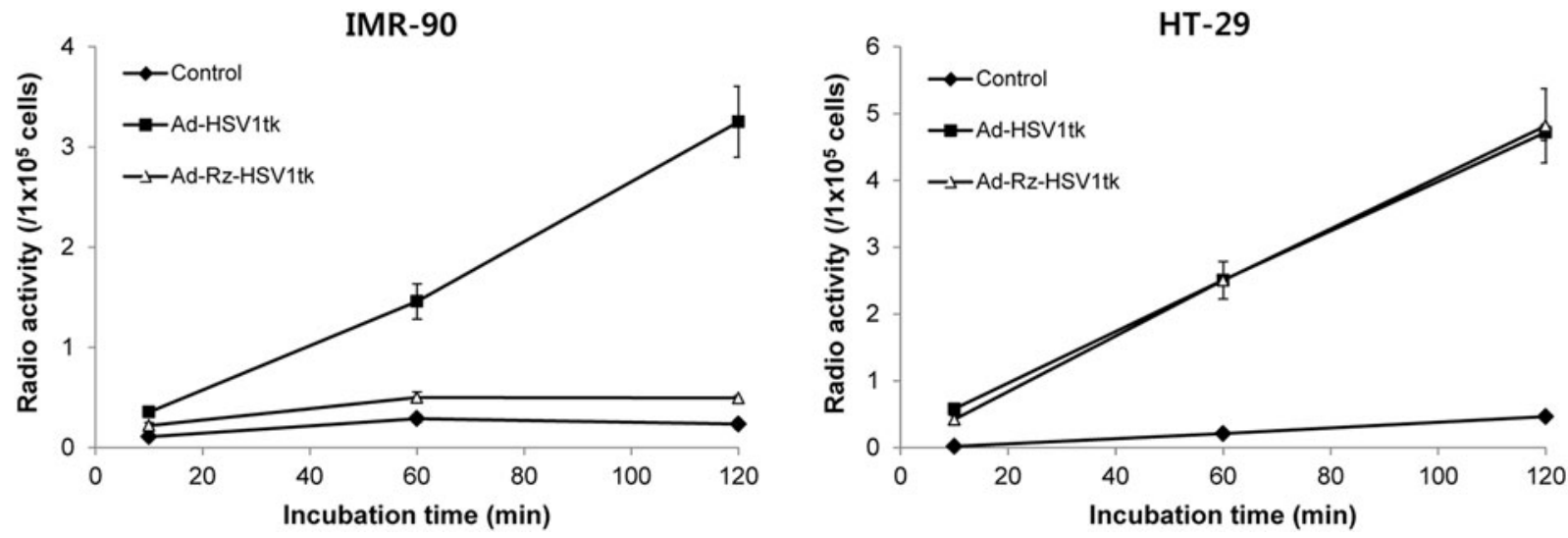

FIG. 3. The hTERT RNA-dependent HSV1-tk activity. Time-dependent selective induction of HSV1-tk activity by hTERT ribozyme was detected by $\left[{ }^{125}\right.$ I]FIAU uptake in HT-29 and IMR-90 cells. 
A

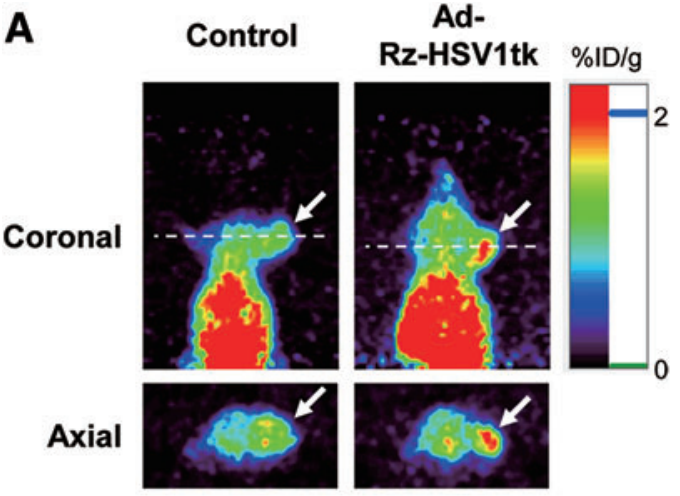

B

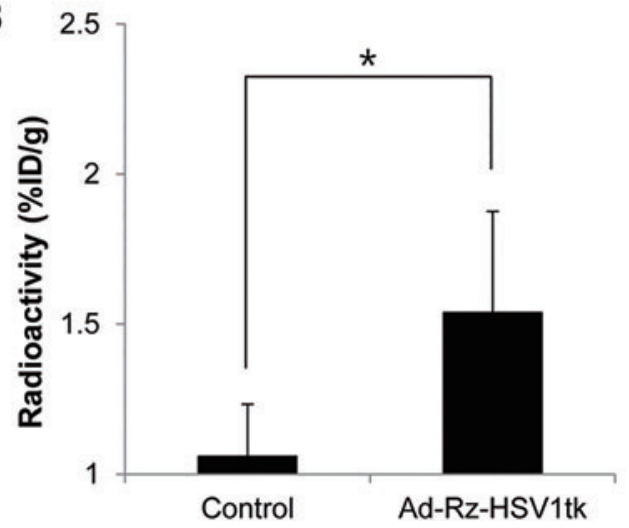

FIG. 4. $\left[{ }^{124}\right.$ I]FIAU uptake by efficient targeting of Ad-RzHSV1tk in HT-29 tumor-bearing mice. (A) Representative small animal PET images in control $(n=5)$ and Ad-RzHSV1tk $(n=5)$-injected mice, respectively, (B) tumor ROI analysis $(* p<0.05)$. Arrows indicate HT-29 tumors. ROI, region of interest. Color images are available online.

Ad-Rz-HSV1tk-infected HT-29 tumor showed higher levels of $\left[{ }^{124}\right.$ I]FIAU uptake than Ad-Rz-HSV1tk-infected muscle $(n=3)$. These data indicate that Ad-Rz-HSV1tk-infected hTERT-positive tumor can be noninvasively detected by PET imaging with $\left[{ }^{124}\right.$ I]FIAU.

\section{Biodistribution of [ ${ }^{124}$ I]FIAU in HT-29 tumor-bearing mice}

To investigate hTERT-positive cancer targeting by hTERT-specific TSR, the authors performed biodistribution analysis with a $\gamma$-counter after a $48 \mathrm{~h}$ injection with $\left[{ }^{124}\right.$ I]FIAU. Biodistribution results showed also high levels of $\left[{ }^{124}\right.$ I]FIAU uptake in the Ad-Rz-HSV1tk-injected HT-29 tumor along with PET/computed tomography (CT) images acquired at $24 \mathrm{~h}$ after adenovirus injection in the same mice (Fig. 6). Furthermore, it has high specificity based on tumor-to-muscle (18.38-fold) and tumor-to-blood (11.5fold) ratios obtained from the biodistribution data (Table 1). Furthermore, Ad-Rz-HSV1tk-injected tumor uptake was 6.27fold higher compared with the control tumor. In this study, the highest uptake of $\left[{ }^{124}\right.$ I]FIAU was detected in the small intestine, which was consistent with a previous study, suggesting urinary excretion of FIAU through the small intestine. $^{24}$

\section{Discussion}

The viral tk has broader substrate specificity than mammalian tk and phosphorylates the pyrimidine and purine nucleoside derivatives, as well as deoxythymidine. ${ }^{25}$ The thymidine derivative, FIAU, has been used as a reporter probe for HSV1-tk gene expression monitoring by radioiodination. ${ }^{26}$ It is transported into a cell and is phosphorylated by activated HSV1-tk, and is incorporated into the DNA. $^{27}$ The authors detected $\left[{ }^{125}\right.$ I]FIAU only in the hTERT-positive cells and not in the hTERT-negative cells, even though ribozymes (represented as HSV1-tk RNA production) were present in the hTERT-negative cells (Figs. 2A and 3) due to the absence of hTERT-dependent splicing by ribozyme in hTERT-negative cells. These data suggest that the methods using Ad-Rz-HSV1tk and $\left[{ }^{125}\right.$ I]FIAU might represent a highly effective diagnostic and therapeutic strategy in hTERT-positive cancer.

FIAU is labeled with the positron-emitting radionuclide ${ }^{124} \mathrm{I}\left(\mathrm{T}_{1 / 2}=4.08 \mathrm{~d}\right)$. Tjuvajev et al. demonstrated that analysis using [ ${ }^{124}$ I]FIAU reporter probe is a highly specific noninvasive imaging modality to identify and quantitate HSV1-tk expression. ${ }^{28}$ Also, Kim et al. reported that $\left[{ }^{125}\right.$ I]FIAU single-photon emission computed tomography (SPECT) and $\left[{ }^{18} \mathrm{~F}\right] \mathrm{FHBG}$ PET contributed to evaluation of successfully
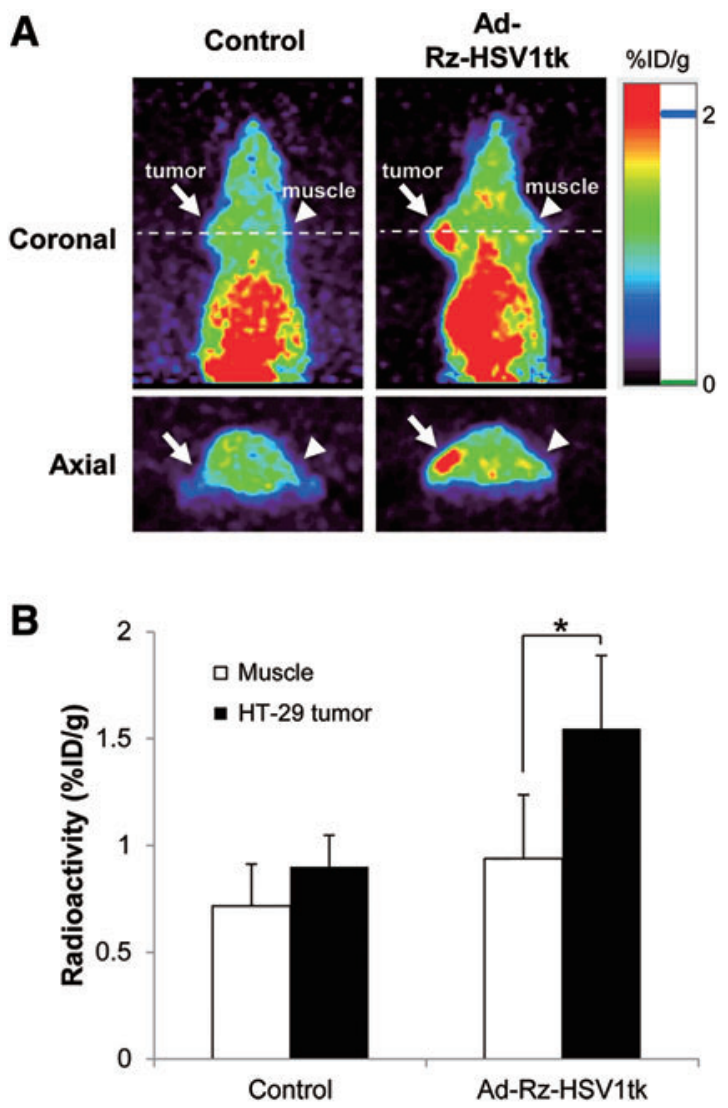

FIG. 5. Comparison of $\left[{ }^{124} \mathrm{I}\right]$ FIAU uptake by muscle and tumor in HT-29 tumor-bearing mice. (A) Small animal PET images in control $(n=2)$ and Ad-Rz-HSV1tk $(n=3)$-injected mice, (B) ROI analysis $(* p<0.05)$. Arrows and arrow heads indicate HT-29 tumors and muscle, respectively. Color images are available online. 


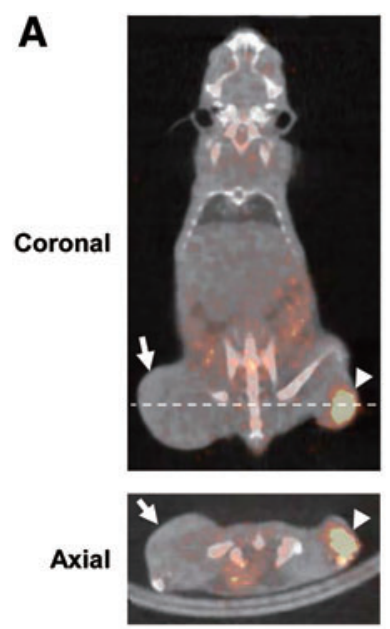

targeted gene expression of pancreatic adenocarcinoma upregulated factor-targeting TSR and liver-specific hTERTtargeting TSR in pancreatic cancer and hepatocellular carcinoma mice model, respectively. ${ }^{29,30}$ Also, another similar research for hTERT targeting had been done about combining the HSV1-tk with retrovirus vector in the therapy of hepatocellular carcinoma, development of the multimodal imaging probe using hTERT antibody, and the $\left[{ }^{18} \mathrm{~F}\right] \mathrm{FDG}$ PET/CT imaging and serum hTERT mRNA quantification in cancer diagnosis. $^{31-33}$

However, in this study, the authors used adenoviral vector system for cancer-specific HSV1-tk expression by ribozyme and they conducted hTERT-specific TSR-targeted imaging using PET, which showed higher sensitivity and spatial resolution than SPECT. Moreover, they showed whole-body PET imaging with [ $\left.{ }^{124} \mathrm{I}\right] \mathrm{FIAU}$, which has greater sensitivity, dynamic range, and lower abdominal background radioactivity than $\left[{ }^{18} \mathrm{~F}\right] \mathrm{FHBG} .{ }^{34}$ Figures 4 and 5 indicate that $\left[{ }^{124}\right.$ I]FIAU PET imaging can be effectively used to verify HSV1-tk RNA replacement by TSR. These data demonstrate that $\left[{ }^{124}\right.$ I]FIAU can be utilized to quantitatively evaluate HSV1-tk gene expression by hTERT-specific TSR.

\section{Table 1. Biodistribution Results of [ ${ }^{124}$ I]FIAU AT $24 \mathrm{H}$ AFTER PET/CT IMAGING In the SAme Tumor-Bearing Mice $(n=3)$}

\begin{tabular}{lcc}
\hline Tissue & $\% I D / g$ & $\begin{array}{c}\text { Ad-Rz-HSVltk } \\
\text { tumor-to-tissue ratio }\end{array}$ \\
\hline Blood & $0.02 \pm 0.02$ & $17.79 \pm 13.25$ \\
Heart & $0.02 \pm 0.01$ & $18.04 \pm 15.45$ \\
Liver & $0.04 \pm 0.02$ & $7.04 \pm 6.95$ \\
Lung & $0.05 \pm 0.03$ & $6.45 \pm 5.06$ \\
Spleen & $0.15 \pm 0.06$ & $2.37 \pm 2.25$ \\
Kidney & $0.05 \pm 0.02$ & $6.48 \pm 4.51$ \\
Stomach & $0.07 \pm 0.04$ & $5.70 \pm 4.11$ \\
Small intestine & $0.59 \pm 0.08$ & $0.47 \pm 0.27$ \\
Large intestine & $0.19 \pm 0.12$ & $1.92 \pm 1.40$ \\
Muscle & $0.01 \pm 0.01$ & $28.84 \pm 23.85$ \\
Control tumor & $0.04 \pm 0.01$ & $6.72 \pm 3.98$ \\
Ad-Rz-HSV1tk tumor & $0.26 \pm 0.13$ & 1.00 \\
\hline
\end{tabular}

Data are presented as mean \pm standard deviation for 3 animals.

CT, computed tomography; $\left[{ }^{124} \mathrm{I}\right] \mathrm{FIAU},{ }^{124} \mathrm{I}$ labeled $2^{\prime}$-fluoro- $2^{\prime}$ deoxy-1- $\beta$-D-arabinofuranosyl-5-iodouracil; $\% \mathrm{ID} / \mathrm{g}, \%$ injected dose per gram of tissue; PET, positron emission tomography.

\section{Conclusions}

In summary, the authors demonstrated that the HSV1-tk trans-splicing activity with TSR depends on the presence of hTERT. The trans-splicing activity is attributed to selective detection of the hTERT-positive tumor. Furthermore, they demonstrated that hTERT-specific uptake of $\left[{ }^{124} \mathrm{I}\right]$ FIAU reporter probe provides PET imaging and quantification of therapeutic gene expression. These results contribute to diagnostic assessment and gene therapy by hTERT-specific TSR in hTERT-positive cancer.

\section{Authors' Contributions}

M.J.S.: conception (constructing the idea for research and the article); data collection (execution of the experiments); analysis and interpretation (interpretation and presentation of the results); data processing (taking responsibility in data management and reporting); literature review; and writer (taking responsibility in the construction of the article). J.H.P.: data collection (execution of the experiments) and literature review. K.C.L.: data collection (execution of the experiments) and critical review (reviewing the article before submission). Y.J.L. and T.S.L.: conception (constructing the idea for research) and critical review (reviewing the article before submission). T.H.C.: data collection (execution of the experiments) and analysis and interpretation (interpretation and presentation of the results). S.W.L.: data collection (execution of the experiments); conception (constructing the idea for research); and critical review (reviewing the article before submission). K.I.K.: conception (constructing the idea for research); design (planning methodology to reach the conclusion); data collection (taking responsibility in execution of the experiments); analysis and interpretation (interpretation and presentation of the results); and critical review (reviewing the article before submission). J.H.K.: conception (constructing the idea for research); design (planning methodology to reach the conclusion); analysis and interpretation (interpretation and presentation of the results); and critical review (reviewing the article before submission).

\section{Disclosure Statement}

There are no existing financial conflicts. 


\section{Funding Information}

This work was supported by the National Research Foundation of Korea (NRF) grant funded by the Ministry of Science and ICT (NRF-2015R1C1A1A02036885, NRF2017M2A2A02070985, and NRF-2017R1A2B2003368).

\section{References}

1. McCormick F. Cancer gene therapy: Fringe or cutting edge? Nat Rev Cancer 2001;1:130.

2. Jones JT, Lee SW, Sullenger BA. Tagging ribozyme reaction sites to follow trans-splicing in mammalian cells. Nat Med 1996;2:643.

3. Shin KS, Sullenger BA, Lee SW. Ribozyme-mediated induction of apoptosis in human cancer cells by targeted repair of mutant p53 RNA. Mol Ther 2004;10:365.

4. Kwon BS, Jung HS, Song MS, et al. Specific regression of human cancer cells by ribozyme-mediated targeted replacement of tumor-specific transcript. Mol Ther 2005;12: 824.

5. Won YS, Lee SW. Targeted retardation of hepatocarcinoma cells by specific replacement of alpha-fetoprotein RNA. J Biotechnol 2007;129:614.

6. Jeong JS, Lee SW, Hong SH, et al. Antitumor effects of systemically delivered adenovirus harboring trans-splicing ribozyme in intrahepatic colon cancer mouse model. Clin Cancer Res 2008;14:281.

7. Kim KI, Chung JK, Kang JH, et al. Visualization of endogenous p53-mediated transcription in vivo using sodium iodide symporter. Clin Cancer Res 2005;1:123.

8. Kim KI, Park JJ, Lee YJ, et al. Gamma camera and optical imaging with a fusion reporter gene using human sodium/iodide symporter and monomeric red fluorescent protein in mouse model. Int J Radiat Biol 2011;87: 1182.

9. Kim KI, Park JH, Lee YJ, et al. In vivo bioluminescent imaging of $\alpha$-fetoprotein-producing hepatocellular carcinoma in the diethylnitrosamine-treated mouse using recombinant adenoviral vector. J Gene Med 2012;14:513.

10. Brader P, Serganova I, Blasberg RG. Noninvasive molecular imaging using reporter genes. J Nucl Med 2013;54: 167.

11. Hasegawa S, Choi JW, Rao J. Single-cell detection of trans-splicing ribozyme in vivo activity. J Am Chem Soc 2004;126:7158.

12. So MK, Gowrishankar G, Hasegawa $S$, et al. Imaging target mRNA and siRNA-mediated gene silencing in vivo with ribozyme-based reporters. Chembiochem 2008;9:2682.

13. Hong SH, Jeong JS, Lee YJ, et al. Molecular imaging of endogenous mRNA expression in a mouse tumor model by adenovirus harboring trans-splicing ribozyme. FEBS Lett 2007;581:5396.

14. Luker GD, Luker KE. Optical imaging: Current applications and future directions. J Nucl Med 2008;49:1.

15. Tjuvajev JG, Stockhammer G, Desai R, et al. Imaging the expression of transfected genes in vivo. Cancer Res.1995; 55:6126.

16. Jang SJ, Kang JH, Kim KI, et al. Application of bioluminescence imaging to therapeutic intervention of herpes simplex virus type I-Thymidine kinase/ganciclovir in glioma. Cancer Lett 2010;297:84.

17. Jang SJ, Lee YJ, Lim S, et al. Imaging of a localized bacterial infection with endogenous thymidine kinase using radioisotope-labeled nucleosides. Int $\mathrm{J}$ Med Microbiol 2012;302:101.

18. Park JH, Kim KI, Lee KC, et al. Assessment of $\alpha-$ fetoprotein targeted HSV1-tk expression in hepatocellular carcinoma with in vivo imaging. Cancer Biother Radiopharm 2015;30:8.

19. Shields AF, Grierson JR, Kozawa SM, et al. Development of labeled thymidine analogs for imaging tumor proliferation. Nucl Med Biol 1996;23:17.

20. Chou TC, Feinberg A, Grant AJ, et al. Pharmacological disposition and metabolic fate of 2'-fluoro-5-iodo-1-betaD-arabino furanosylcytosine in mice and rats. Cancer Res 1981;41:3336.

21. Doubrovin M, Ponomarev V, Beresten T, et al. Imaging transcriptional regulation of p53-dependent genes with positron emission tomography in vivo. Proc Natl Acad Sci U S A 2001;98:9300.

22. Choi TH, Ahn SH, Kwon HC, et al. In vivo comparison of IVDU and IVFRU in HSV1-TK gene expressing tumor bearing rats. Appl Radiat Isot 2004;60:15.

23. Lee SJ, Lee SW, Jeong JS, et al. In vivo reprogramming of human telomerase reverse transcriptase (hTERT) by transsplicing ribozyme to target tumor cells. Methods Mol Biol 2010;629:307.

24. Ruggiero A, Brader P, Serganova I, et al. Different strategies for reducing intestinal background radioactivity associated with imaging HSV1-tk expression using established radionucleoside probes. Mol Imaging 2010;9:47.

25. Gentry GA. Viral thymidine kinases and their relatives. Pharmacol Ther 1992;54:319.

26. Mankoff DA, Shields AF, Krohn KA. PET imaging of cellular proliferation. Radiol Clin North Am 2005;43:153.

27. Morin KW, Duan W, Xu L, et al. Cytotoxicity and cellular uptake of pyrimidine nucleosides for imaging herpes simplex type-1 thymidine kinase (HSV-1 TK) expression in mammalian cells. Nucl Med Biol 2004;31:623.

28. Tjuvajev JG, Avril N, Oku T, et al. Imaging herpes virus thymidine kinase gene transfer and expression by positron emission tomography. Cancer Res 1998;58:4333.

29. Kim YH, Moon JY, Kim EO, et al. Efficient targeting and tumor retardation effect of pancreatic adenocarcinoma up-regulated factor (PAUF)-specific RNA replacement in pancreatic cancer mouse model. Cancer Lett 2014; 344:223.

30. Kim YH, Kim KT, Lee SJ, et al. Image-aided suicide gene therapy utilizing multifunctional hTERT-targeting adenovirus for clinical translation in hepatocellular carcinoma. Theranostics 2016;6:357.

31. Li H, Wang Q, Li D, et al. Combination of HSV1-TK/ shTERT by retrovirus vector inhibits hepatocellular carcinoma cell growth in vitro and in vivo. Oncol Rep 2015;33: 1307.

32. Jung KO, Youn H, Kim SH, et al. A new fluorescence/PET probe for targeting intracellular human telomerase reverse transcriptase (hTERT) using Tat peptide-conjugated IgM. Biochem Biophys Res Commun 2016; 477:483.

33. Ping B, Tsuno S, Wang X, et al. Comparative study of $\left[{ }^{18}\right.$ F $]$ FDG PET/CT imaging and serum hTERT mRNA quantification in cancer diagnosis. Cancer Med 2015;4: 1603.

34. Tjuvajev JG, Doubrovin M, Akhurst T, et al. Comparison of radiolabeled nucleoside probes (FIAU, FHBG, and FHPG) for PET imaging of HSV1-tk gene expression. J Nucl Med 2002;43:1072. 